\title{
Electrochemical Study of the Capacity of Moringa oleifera to Chelate Heavy Metals
}

Zaroual A ${ }^{1}$, El Qouatli $\mathbf{S}^{2}$, Bellochou $\mathbf{A}^{1}$, Najih $\mathbf{R}^{2}$ and Chtaini $\mathbf{A}^{2 *}$

${ }^{1}$ Laboratory corrosion- Electrochemistry, Faculty of Sciences of Rabat, Morocco

${ }^{2}$ Equipe of Molecular Electrochemistry and Inorganic Materials, Sultan Moulay Slimane University, Faculty of Science and Technology of Beni Mellal, Morocco

\begin{abstract}
We report a sensitive electrochemical voltammetric method for analyzing heavy metals, such, $\mathrm{Pd}^{2+}$ and $\mathrm{Cd}^{2+} \mathrm{using}$ a modified carbon paste electrodes. Operational parameters have been optimized, and the stripping voltammetric performance has been studied using square wave voltammetry. The use of Moringa oleifera as natural chelating agent gave a significant improvement in the depollution of contaminated water sample.
\end{abstract}

Keywords: Electroanalysis; Modified electrodes; Heavy metals; Moringa oleifera

\section{Introduction}

Heavy metals have become of particular interest in recent decades within the framework of environmental investigation. This has without doubt been due to the fact that highly sensitive analytical procedures are available for determining and detecting metal content with high precision. Lead, for example, is a toxic heavy metal that appears in the environment mainly due to industrial processes, it is a microelement naturally present in trace amounts in all biological materials, it has no physiological function in the organism. Lead is absorbed by plants through roots where most of the lead is also accumulated. Lead enters the organism with food and air. In children it affects most the central nervous system [1]. Therefore sensitive methods must be established for the trace amounts of lead quantification in human's body fluids, water samples, plants and animals. Some of the methods used for the determination of lead are Atomic Absorption Spectrometry (AAS) [2,3], Atomic Emission Spectrometry (AES) [4] and Mass Spectrometry (MS).

These methods, although highly sensitive, require relatively large volumes of sample for analysis, complicated operation, costly maintenance, expensive apparatus and low electrical power requirement [5]. Electrochemical methods are well known as very powerful techniques for determination of diverse range of metallic and biological targets in environmental, biological and industrial samples.

Modified electrodes are also attracting interest [6,7]. Recent works, reported in the literature, have shown several applications and electro analytical methodologies employing micro-electrodes as working electrodes [8-12]. Mercury based electrodes such as, mercury film electrodes and hanging mercury drop electrodes, has been traditionally used in stripping techniques because of their advantages such as high sensitivity, reproducibility, purity of the surface, high hydrogen over potential, and possibility of the amalgam formation and they have been recognized as the most sensitive electrodes for determination of heavy metals [13]. It has been shown that bismuth film electrodes maintain all the advantages of mercury electrodes and, at the same time, are environmentally friendly as the toxicity of bismuth and its salts is negligible. In addition to their lower toxicity, bismuth film electrodes resulted in compared to the performance of mercury electrodes were less sensitive to dissolved oxygen and had a wide potential window for analysis. However, the determination of copper using bismuth film electrodes has been relatively ignored due to the similar stripping potentials of copper and bismuth with only a few reports in the open literature $[11,12]$.

Many researchers detected heavy metal ions at modified carbon paste electrode [12], but no researchers using deposited carbon paste onto steel as electrode for the detection of $\mathrm{Pb}$ (II) were reported. In this work we prepared and characterized the copper modified carbon paste electrode, which successfully exploits the favorable mechanical and electrochemical properties of carbon paste electrodes. Also, this study therefore focused on the determination of the effectiveness of the Moringa oleifera in the purification of water contaminated by heavy metals.

\section{Experimental}

\section{Reagents}

Potassium nitrate was dissolved into Bidistilled Deionized Water (BDW) to form $1 \mathrm{mg} \cdot \mathrm{L}^{-1}$ stock solutions. Working standards for calibration were prepared by diluting the primary stock solution with BDW. Carbon paste was supplied from (Carbon, Lorraine, ref. 9900, French). All chemicals were of analytical grade and used without further purification.

\section{Electrodes preparation}

Firstly, the carbon-paste electrode was prepared according the following procedure [13]. The carbon-paste electrode was prepared by mixing the graphite powder with paraffin oil used as a binder. The mixture was grinding in a mortar agate and then a portion of the resulting composite material was housed in PTFE cylinder. The geometric surface area of the working electrode was $0.1256 \mathrm{~cm}^{2}$. A bare of carbon vitreous inserted into carbon paste provided the electrical contact, and then the copper film is electro deposited onto carbon paste

*Corresponding author: Abdelilah Chtaini, Equipe of Molecular Electrochemistry and Inorganic Materials, Sultan Moulay Slimane University, Faculty of Science and Technology of Beni Mellal, Morocco, +212523485112; Fax:+212523485201 E-mail : a.chtaini@usms.ma

Received August 25, 2014; Accepted September 27, 2014; Published September 30, 2014

Citation: Zaroual A, El Qouatli S, Bellochou A, Najih R, Chtaini A (2014) Electrochemical Study of the Capacity of Moringa oleifera to Chelate Heavy Metals. Pharm Anal Acta 5: 310. doi:10.4172/2153-2435.1000310

Copyright: ( 2014 Zaroual A, et al. This is an open-access article distributed unde the terms of the Creative Commons Attribution License, which permits unrestricted use, distribution, and reproduction in any medium, provided the original author and source are credited. 


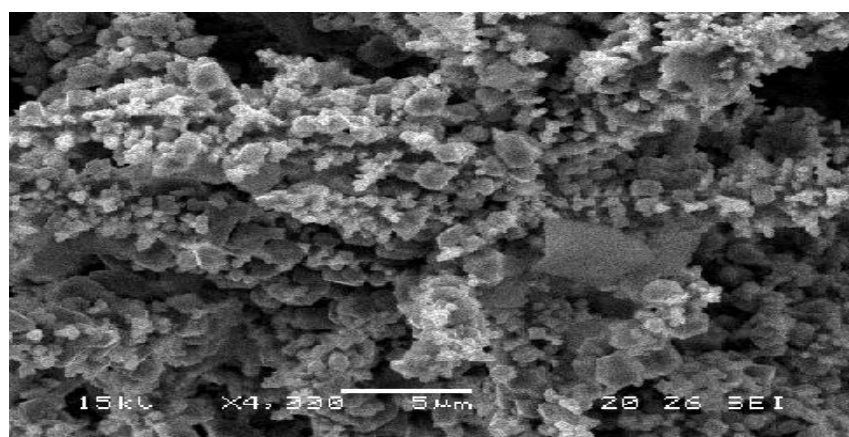

Figure 1: Scanning electron micrograph of Cu-CPE.

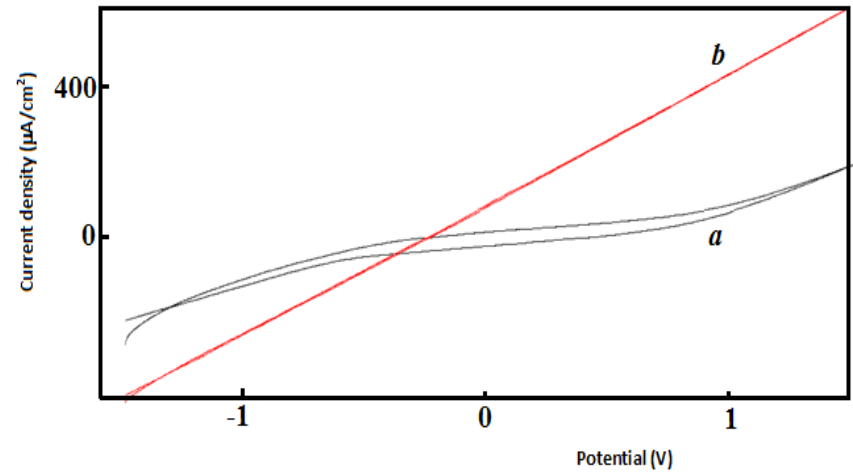

Figure 2: Cyclic voltammograms recorded in electrolytic solution at 100 $\mathrm{mV} / \mathrm{s}$ at a- carbon paste electrode, b- copper modified carbon paste electrode.

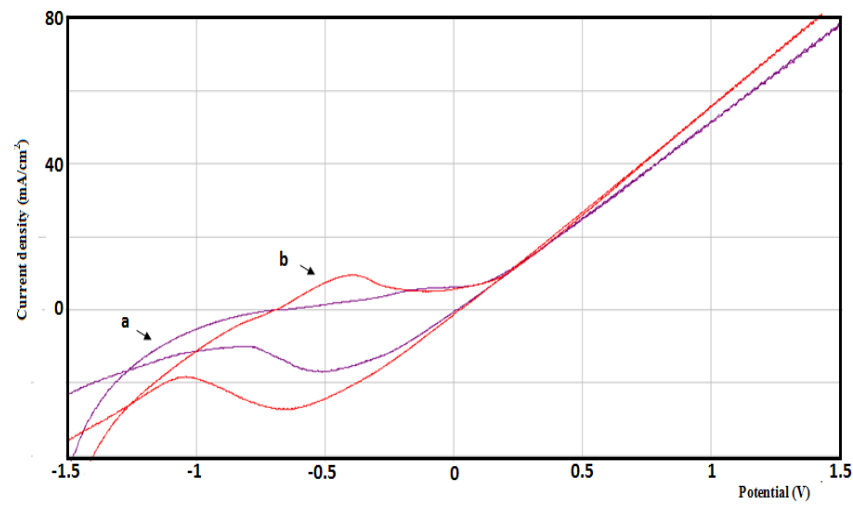

Figure 3: Cyclic voltammograms recorded in electrolytic solution, at 100 $\mathrm{mV} / \mathrm{s}$, at copper modified carbon paste electrode, in $0.1 \mathrm{M} \mathrm{Na}_{2} \mathrm{SO}_{4}$ solution

(a), and after exposing to cadmium solution.

electrode. The deposit of copper on carbon paste electrode surfaces was processed at $20 \mathrm{~V}$. The current was maintained by a galvanostat with a function generator.

\section{Prepared electrode characterization}

All the electrochemical experiments were performed in a standard one-compartment three-electrode cell. The reference electrode was SCE and the counter electrode was platinum. All electrode potentials were referred to this reference electrode. The working electrode was copper modified Carbon Paste Electrode (Cu-CPE).

\section{Apparatus}

Electrochemical experiments were performed using a voltalab potentiostat (model PGSTAT 100, Eco Chemie B.V., Ultrecht, The Netherlands) driven by the general purpose electrochemical systems data processing software (Volta lab master 4 software).

\section{Results and Discussion}

\section{Characterization of prepared electrodes surfaces}

The surface structure of copper modified carbon paste surface was observed using scanning electron microscopy (Figure 1). The film layer of copper was formed on the surface of carbon paste electrode; it was not disintegrated or detached from the surface when immersed in the electrolytic Solution $\left(0.1 \mathrm{M} \mathrm{Na}_{2} \mathrm{SO}_{4}\right)$.

The Cyclic Voltammograms (CVs) of the copper modified Carbon Paste Electrode (Cu-CPE) and Carbon Paste Electrode (CPE) were recorded in the supporting electrolyte $\left(0.1 \mathrm{M} \mathrm{Na}_{2} \mathrm{SO}_{4}\right)$ (Figure 2). We can see that the shape of the cyclic voltammogram was modified in the presence of copper at CPE surface, suggesting that the carbon paste electrode was effectively modified by copper.

\section{Electrochemical detection of studied metals}

The experimental conditions have been optimized and the response characteristics determined in a previous work [13]. The results obtained are:

$$
\cdot \mathrm{pH} \approx 7.2
$$

- Preconcentration time $=15 \mathrm{~min}$.

In order to avoid the strong residual of reduction, the starting potential was fixed at $-1.5 \mathrm{~V}$ versus SCE. Figure 3 shows a cyclic voltammograms performed between-1.5 $\mathrm{V}$ and $1.5 \mathrm{~V}$ for $\mathrm{Cu}-\mathrm{CPE}$, in $0.1 \mathrm{M} \mathrm{Na}_{2} \mathrm{SO}_{4}$ solution (curve a), and in $0.1 \mathrm{M} \mathrm{Na}_{2} \mathrm{SO}_{4}$, after exposure $\mathrm{Cu}-\mathrm{CPE}$ to $1.0 .10^{-6} \mathrm{~mol} / \mathrm{L} \mathrm{Cd}^{2+}$ for $15 \mathrm{~min}$, in a stirred solution (curve b). The reversible system could be observed at $\mathrm{Cu}-\mathrm{CPE}$, with cathodic potential value, of $-0.6 \mathrm{~V}$ and anodic potential value of $-0.4 \mathrm{~V}$.

The Square Wave Voltammetry (SWV) corresponding to the determination of $\mathrm{Cd}^{2+}$, was recorded in the supporting electrolyte (curve a) and after, 15 min of accumulation in a solution containing Cd (II) (curve b). The voltammograms are showed in Figure 4. A well-defined and enhanced peak is observed at $\mathrm{Cu}-\mathrm{CPE}$, imprinted in cadmium solution. This peak is attributed to cadmium oxidation.

The performance of the $\mathrm{Cu}-\mathrm{CPE}$ is tested to, on the preconcentration

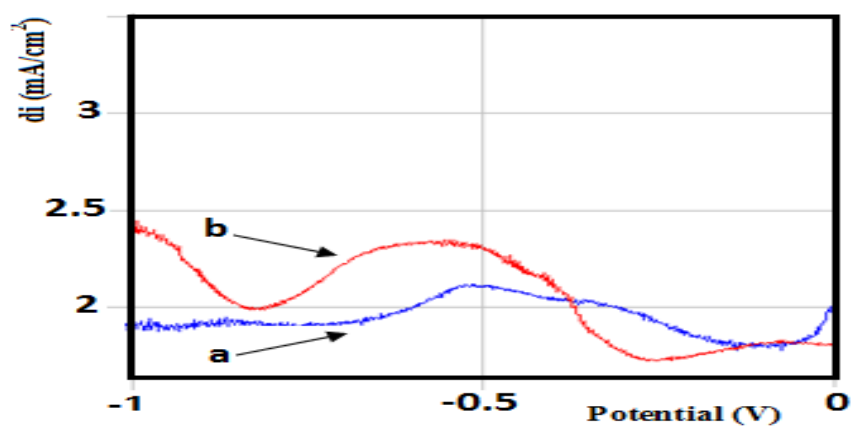

Figure 4: Square wave voltammograms obtained for Cu-pectivelly, in supporting solution (a), and after exposing electrode to cadmium solution. 


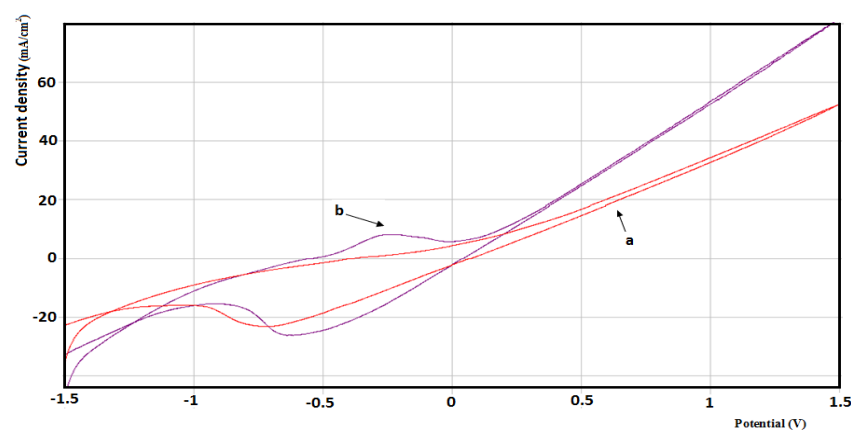

Figure 5: Cyclic voltammograms recorded in electrolytic solution, at 100 $\mathrm{mV} / \mathrm{s}$, at copper modified carbon paste electrode, in $0.1 \mathrm{M} \mathrm{Na}_{2} \mathrm{SO}_{4}$ solution (a), and after exposing to lead solution.

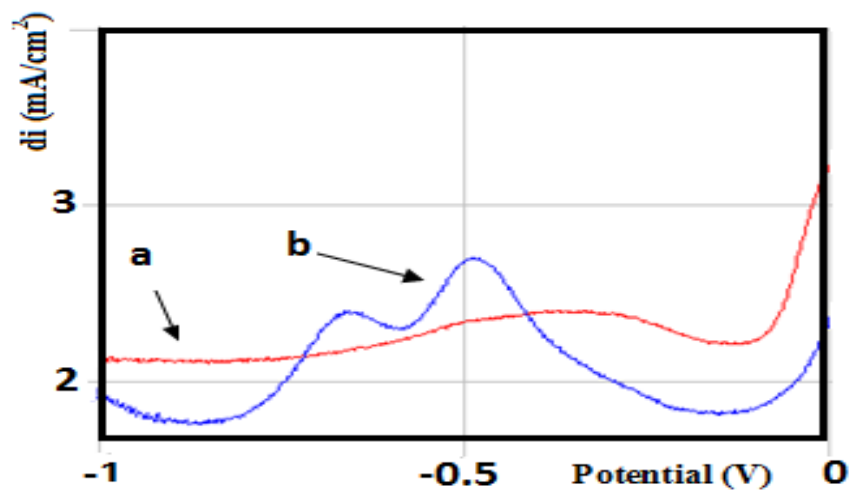

Figure 6: Square wave voltammograms obtained for Cu-respectively, in supporting solution (a), and after exposing electrode to lead solution.

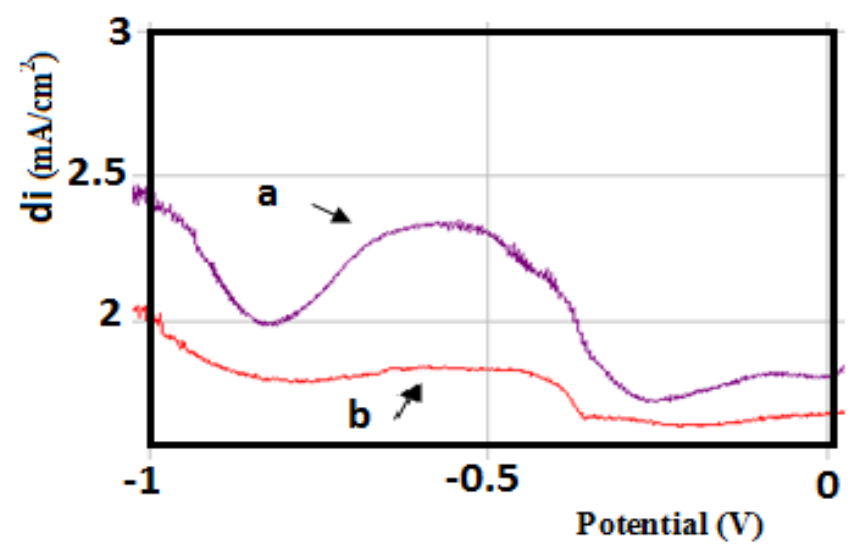

Figure 7: Square wave voltammograms obtained for Cu-respectively, in supporting solution, after exposing electrode to $\mathrm{Cd}^{2+}$ contaminated solution. (a) - before moringa treatment, $\mathrm{b}$ - after moringa treatment.

of $\mathrm{Pb}^{2+}$ from aqueous solution. As can be seen from Figures 5 and 6 , two peaks appears, respectively, in SQW and cyclic voltammograms, the first one attributed to $\mathrm{Pb}^{2+}$ reduction, at $-0.6 \mathrm{~V}$, the second at $-0.7 \mathrm{~V}$ corresponding to the oxidation of $\mathrm{Pb}^{2+}$.

\section{Chelating effect of Moringa oleifera}

Moringa oleifera is the best known species of the Moringaceae family.
Moringaceae is a family of plants belonging to the order Brassicales. It is represented by fourteen species and a single genus (Moringa), being considered an angiosperm plant. It is a shrub or small tree which is fast growing, reaching 12 meters in height. It has an open crown and usually a single trunk. It grows mainly in the semi-arid tropics and subtropics. Since its preferred habitat is dry sandy soil, it tolerates poor soils, such as those in coastal areas [14].

Firstly, the Moringa oleifera was prepared according the following procedure [15]. Moringa oleifera seeds collected for the analysis were shelled off and sun-dried to maintain constant weight. The sun-dried seeds were grinded into powdered form using machine. The powdered was added to the solutions containing heavy metals. After $15 \mathrm{~min}$ of contact with Moringa oleifera, the solutions were purified and analysis in electrochemical sensor.

The SQWV's recorded at carbon paste electrode modified with copper film, in supporting solution containing $\mathrm{Cd}^{2+}$ (curve a) and after addition of the Moringa oleifera (curve b), are shown in Figure 7. The peak current decreased considerably after Moringa treatment. This current density reduction is due to a sharp decline in $\mathrm{Cd}^{2+}$ and $\mathrm{Pb}^{2+}$ concentrations, which suggests that Moringa has a strong complexing power of heavy metals (Figures 7 and 8). We not that the solution $\mathrm{pH}$ was varied after Moringa treatment. It was decreased from 7.2 to 6.5. The decrease in $\mathrm{pH}$ of the treated solution, suggests to us that the Moringa exchanged two protons against the metal ion. The proposed mechanism is as follows:

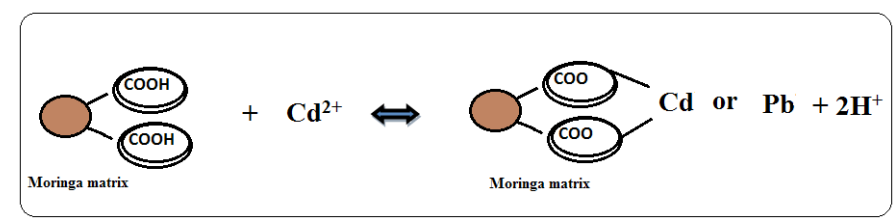

\section{Conclusion}

In conclusion, it was possible demonstrating the potentiality of the proposed electrodes for determining heavy metals. Such a sensor is characterized by a higher sensitivity and reproducibility. The Moringa oleifera seeds have the ability to retain metals. The metal is sequestered by chemical sites naturally present in the Moringa matrix. The chelating process is rapid and takes place under normal temperature and pressure. Moringa oleifera is an environmentally-friendly natural complexing

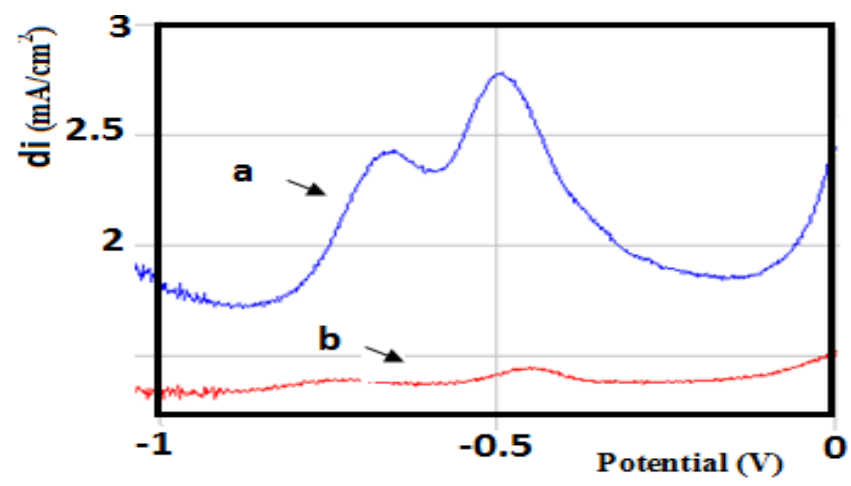

Figure 8: Square wave voltammograms obtained for Cu-respectively, in supporting solution, after exposing electrode to $\mathrm{Pb}^{2+}$ contaminated solution. (a) - before moringa treatment, (b) - after moringa treatment. 
Citation: Zaroual A, El Qouatli S, Bellochou A, Najih R, Chtaini A (2014) Electrochemical Study of the Capacity of Moringa oleifera to Chelate Heavy Metals. Pharm Anal Acta 5: 310. doi:10.4172/2153-2435.1000310

most suitable for the treatment of water containing undesirable heavy metal concentrations. The removal efficiencies were $70 \%$ for $\mathrm{Pb}^{2+}$ and 60 for $\mathrm{Cd}^{2+}$. It is an eco-friendly technology that is economically more advantageous than other treatment alternatives.

\section{References}

1. Smirjakova S, Ondrasovicova O, Kaskova A, Lakticova K (2005) The effect of cadmium and lead pollution on human and animal health. Folia veterinaria 49: S31-S32.

2. McGaw EA, Swain GM (2006) A comparison of boron-doped diamond thinfilm and $\mathrm{Hg}$-coated glassy carbon electrodes for anodic stripping voltammetric determination of heavy metal ions in aqueous media. Anal Chim Acta 575: 180 189.

3. Urbaniczky C, Lundstrom K (1984) Voltammetric studies on carbon paste electrodes: The influence of paste composition on electrode capacity and kinetics. J Electroanal Chem 176: 169-182.

4. Baldwin RP, Christensen JK, Kryger L (1986) Voltammetric determination of traces of nickel(II) at a chemically modified electrode based on dimethylglyoximecontaining carbon paste. Anal Chem 58: 1790-1798.

5. El Mhammedi MA, Bakasse M, Chtaini A (2007) Square-Wave Voltammetric Determination of Paraquat at Carbon Paste Electrode Modified with Hydroxyapatite. Electroanalysis 19: 1727-1733.

6. El Mhammedi MA, Bakasse M, Chtaini A (2007) Electrochemical studies and square wave voltammetry of paraquat at natural phosphate modified carbon paste electrode. J Hazard Mater 145: 1-7.

7. El Mhammedi MA, Bakasse M, Chtaini A (2007)Voltammetric Detection of Diquat at the Carbon Paste Electrode Containing aCa ${ }_{10}\left(\mathrm{PO}_{4}\right)_{6}(\mathrm{OH})_{2}$. Leonardo Electronic Journal of Practices and Technologies 10: 1-12.
8. El Mhammedi MA, Chtaini A (2007) Investigation of the Inhibitive Effect of Pyrazolo [3, 4-b] Pyridine on Corrosion of Stainless Steel in $1 \mathrm{M} \mathrm{HCl} \mathrm{Solutions.}$ Leonardo Electronic Journal of Practices and Technologies 11: 37-46.

9. El Mhammedi MA, Bakasse M, Chtaini A (2008) Investigation of square wave voltammetric detection of diquat at carbon paste electrode impregnated with $\mathrm{Ca}_{10}\left(\mathrm{PO}_{4}\right)_{6} \mathrm{~F}_{2}$ : Application in natural water samples. Mater Chem Phys 109: 519525.

10. El Mhammedi MA, Achak $M$, Chtaini A (2009) $\mathrm{Ca}_{10}\left(\mathrm{PO}_{4}\right)_{6}(\mathrm{OH})_{2}$-modified carbon-paste electrode for the determination of trace lead(II) by square-wave voltammetry. J Hazard Mater 161: 55-61.

11. Legeai S, Bois S, Vittori O (2006) A copper bismuth film electrode for adsorptive cathodic stripping analysis of trace nickel using square wave voltammetry. J Electroanal Chem 591: 93-98.

12. Kachoosangi RT, Banks CE, Ji X, Compton RG (2007) Electroanalytica determination of cadmium(II) and lead(II) using an in-situ bismuth film modified edge plane pyrolytic graphite electrode. Anal Sci 23: 283-289.

13. Ubuoh EA, Akhionbare SMO, Onifade AO (2013) Potential of Moringa - oleifera seed powder as a coagulation agent for refinery wastewater treatment in Warri, Delta State, Nigeria. IJABR 3: 17-20.

14. Da Silva AR, Kerr WE (1999) Moringa: uma nova hortaliça para o Brasil Uberlândia: UFU/ DIRIU.

15. Gomdje VH, Ngono TRL, El quoatli SE, Najih R, Chtaini A (2013) Acta Technica Corviniensis 6: 139-142. 